\title{
Morphosyntactic form of Korean fragments is relevant to their resolution
}

\author{
Joanna Nykiel, Jong-Bok Kim, Rok Sim \& Okgi Kim*
}

\begin{abstract}
We offer evidence for a structural identity constraint between a fragment and the structurally parallel position in the antecedent (which we term correspondent here). We ask if there is a preference for morphosyntactic match (generally in terms of syntactic category, but in terms of case marking in the Korean data discussed here) between a fragment and its correspondent. This question follows from the idea that in order to interpret fragments, the parser directly accesses content-addressable representations stored in memory, using as retrieval cues the linguistic information that fragments provide. We explore this preference using experimental data from Korean. In three acceptability judgment experiments, we demonstrate that (1) morphosyntactic match between fragments and correspondents is favored over mismatch, (2) the acceptability of mismatch is directional, favoring fragments that are morphosyntactically less complex than correspondents over the reverse, and (3) caseless fragments are degraded when paired with implicit correspondents compared to explicit ones.
\end{abstract}

Keywords. morphosyntactic match; fragments; sluicing; Korean; direct-access mechanism

1. Introduction. Psycholinguistic research on ellipsis has shown that an antecedent for a fragment is retrieved via a mechanism that allows direct access to content-addressable linguistic representations stored in memory (Martin and McElree 2008, 2009, 2011). In other words, a fragment carries linguistic cues that the processor uses to locate the fragment's correspondent directly, without a serial search through irrelevant representations. Relevant fragments are depicted in examples (1) and (2).

A: Who are you talking to?

B: Mitchell/To Mitchell.

A: Just doing some research.

B: *What/On what?

The fragments we discuss here represent two kinds of clausal ellipsis: sluicing, which involves wh-phrases as fragments, as in (2), and fragment answers, which involve non-wh-phrases as fragments, as in (1). Although our focus is on fragment answers, the distinction between them and sluicing has little bearing on the argument, given well-known similarities between these constructions and shared theoretical analyses of them (see Culicover and Jackendoff 2005, Merchant 2004).

\footnotetext{
*Authors: Joanna Nykiel, Kyung Hee University(joanna.nykiel@khu.ac.kr), Jong-Bok Kim, Kyung Hee University (jongbok@khu.ac.kr), Rok Sim, Kyung Hee University (simrok89@khu.ac.kr) \& Okgi Kim, University of Wisconsin-Milwaukee (okgi.kim@gmail.com).
} 
There is a key difference between the fragments in (1) and (2). The fragments in (1) alternate between an NP and PP, a possibility that is blocked for the fragments in (2). Note that the PP to which the PP fragment in (1) corresponds (Who to) is expressed explicitly in its antecedent. This is not so for the PP fragment in (2): the PP to which it corresponds is expressed implicitly in the antecedent. The fragment must be realized as a PP in this case (see, among others, Chung 2006, 2013, Barros 2014, Weir 2014). A parallel pattern can be seen in the Korean examples in (3)-(4). The fragments in (3) alternate between a case-marked and a caseless NP because their correspondent (mwues-ul) is explicit in the antecedent. When the correspondent is implicit, as in (4), only the case-marked fragment is available.

(3) Korean

A: Mimi-ka mwues-ul masy-ess-ni?

A: Mimi-NOM what-ACC drink-PST-QUE

B: Cwusu-lul/ Cwusu.

B: juice-ACC/juice

'A: What did Mimi drink? B: Juice.'

(4) A: Chelswu-ka pat-ass-ney.

A: Chelswu-NOM recieve-PST-DECL

B: Ung, sangkum-ul/*sangkum.

B: yes prize-ACC/*prize

'A: Chelswu received (something). B: Yes, a prize.'

This ban on case drop closely tracks the ban on preposition drop illustrated in (1)-(2) for English.

In addition to the above patterns, Korean permits structural case markers ${ }^{1}$ to go missing from NPs in full clauses (Lee 2015, Kim 2016). This produces a set-up where a fragment corresponds to a caseless NP in the antecedent clause and can itself be either a caseless NP or a casemarked NP. If case-marked, a fragment must correspond to the case that would be marked on the corespondent if it was present, here accusative, as in (5) (cf. (3) above).

\section{Korean}

A: Mimi-ka mwues masy-ess-ni?

A: Mimi-NOM what drink-PST-QUE?

B: Cwusu-lul/Cwusu.

B: juice-ACC/juice

'A: What did Mimi drink? B: Juice.'

To sum up, there are four ways in which fragments and explicit correspondents can be paired up in Korean. Both can be caseless, both can be case-marked, a fragment can be caseless and the correspondent case-marked, or a fragment can be case-marked and the correspondent caseless.

These data suggest that the process of retrieving an antecedent for a fragment via a directaccess mechanism is impacted by the morphosyntactic information encoded in a fragment. It is a reasonable assumption that the processor identifies the stored representation that best matches

\footnotetext{
${ }^{1}$ For more detail on the difference between structural and semantic case in Korean, see Section 2.
} 
the morphosyntactic cues a fragment carries, and that the efficiency of this process may be affected by the quality of the cues. Martin and McElree (2011) demonstrate that such a direct-access process is susceptible to memory constraints (e.g., interference from similar representations or distance between a fragment and antecedent) in terms of the accuracy of comprehending a fragment, but not in terms of the speed of processing. This finding is consistent with cue-based models of retrieval, where interference created by material intervening between dependent elements may disrupt the processing of the dependency by weakening the specificity of retrieval cues (Van Dyke \& McElree 2006, 2011, Van Dyke 2007). The existing research leaves it unclear, however, what specific retrieval cues a fragment provides to guide the process of accessing the antecedent.

We assume that a fragment's function is to send the processor directly to the fragment's correspondent. We propose that one way to facilitate this process is to match the morphosyntactic information (i.e., syntactic category and case features) of a fragment with that of the correspondent. In fact, Culicover and Jackendoff (2012) argue for three domain-general steps in the resolution of ellipsis, the initial of which is Find, that is, finding a pair of elements to compare. For the constructions discussed here, one element is a fragment and the other is to be found among the stored representations of the constituents of the antecedent, where the target is the fragment's correspondent. Once these elements have been found, their linguistic features are Aligned for comparison so that a decision can be reached as to whether they are different. Culicover and Jackendoff (2012) further suggest that, given the reluctance of ellipsis to accept syntactically nonparallel antecedents (e.g., featuring voice mismatch or nonlinguistic material), aligning the linguistic features of fragments and antecedents is easiest if syntactic parallelism is maintained between them. Following up on this idea, we suggest that syntactic parallelism is maximized if the syntactic category and case features of fragments match those of their correspondents. What this means for the alternation discussed here is that matching fragments and correspondents should be better than mismatching ones.

The rest of the paper proceeds as follows. The next section defends the proposal that syntactic category and case match aids the search for a fragment's correspondent, and the acceptability of mismatch is directional. Here, we also give more precision to the term correspondent, as we use it throughout the paper. In section 3, we present three acceptability judgment experiments that confirm the predictions of our proposal. In section 4, we explore the implications of our findings for theories of ellipsis. Section 5 concludes.

2. Morphosyntactic form match. This section explores reasons why structural match should be advantageous, and why and when departures from it might occur. We begin by reviewing identity constraints that have been imposed on fragments by theoretical accounts of clausal ellipsis.

It is standardly assumed that a fragment corresponds to an explicit or implicit XP in its antecedent. Research that centers around implicit XPs (like those in (2) and (4)) is forced to conclude that a fragment must be selected by the same lexical head that selects the implicit XP, on the additional assumption that a fragment has invisible sentential structure (Chung 2013). Proposals positing no invisible structure for fragments assume a nonlocal relation between fragments and implicit or explicit XPs such that they share the syntactic category and/or case (Culicover \& Jackendoff 2005, 2012, Ginzburg \& Sag 2000, Ginzburg 2012, Kim 2015, Sag \& Nykiel 
2011a,b, Jacobson 2016). Culicover and Jackendoff $(2005,2012)$ derive the behavior of fragments with implicit XPs by specifically requiring that a fragment share the syntactic features associated with the parallel position in the antecedent via indirect licensing. Indirect licensing permits lexical heads to license nonlocally any arguments that are activated as part of their lexical entries during processing even if these arguments are present only implicitly in the antecedent structure. The data in (2) and (4) are thus successfully captured. However, it is less clear how the alternating fragments in (1) and (3) correspond to a specific XP in the antecedent clauses. In section 1, we take as the correspondents the XPs that the larger fragments correspond to, that is, a PP in (1) and a case-marked NP in (3). This is turn implies that both fragments correspond to a single XP and that the smaller fragments are reduced versions of their correspondents. Below we argue that this is the correct approach.

We argue specifically that the possibilities for realizing a fragment are at least the same as the possibilities for realizing the parallel position in the argument structure of the antecedent clause. This is clear from the Korean examples in (3) and (5), where the fragments may be either case-marked or caseless, just like the parallel direct object positions. It is equally clear from the English examples in (1)-(2), where the fragments may be realized as PPs since the parallel positions are also PPs.

More supportive evidence comes from Bulgarian and Dutch. The Bulgarian case system makes two cases available for pronominal objects: the general case $(\mathrm{G})$, which also extends to pronominal subjects, and the non-subject case (NON-S), which is limited to verbal and prepositional objects. As (6)-(7) show, either of these cases may be used by the pronominal verbal objects and by the corresponding sluicing fragments (Abels 2017b, ex. 34). Abels (2017b) notes there is a bias for matching forms: fragments usually pick the same case as that currently marked on the parallel positions.

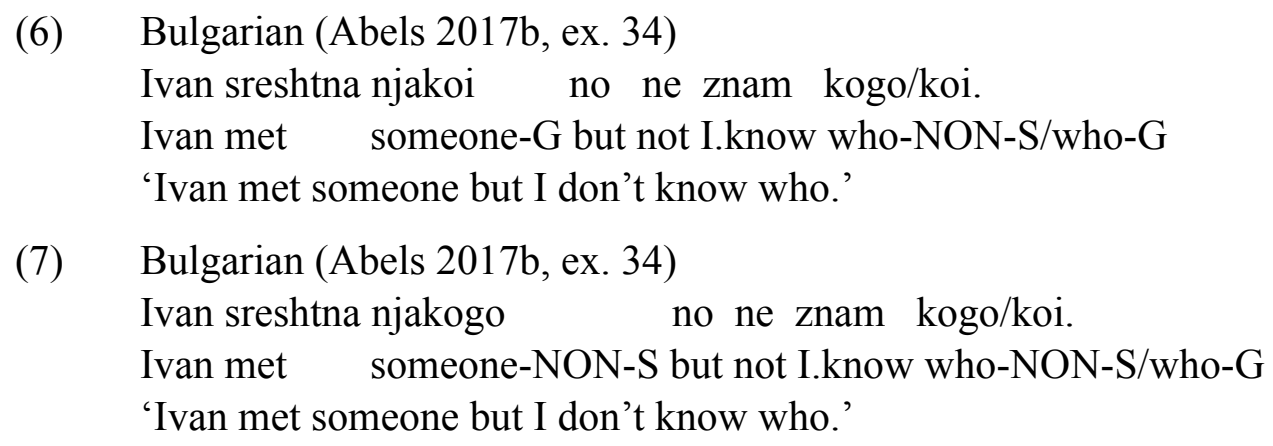

Similarly, the Dutch verb laten 'let' selects for a PP (8) or an NP (9), and fragments may be realized as either PPs or NPs, mirroring the possibilities available for the arguments selected by laten (Levelt \& Kelter 1982). At the same time, Levelt \& Kelter (1982) observed a preference for matching syntactic categories, which they term a 'correspondence effect'.

Dutch (Levelt \& Kelter 1982: 80)

A: Aan wie laat Paul zijn viool zien?

A: to whom lets Paul his violin see

B: Aan Toos/Toos.

B: to Toos/Toos 
'A: Who does Paul allow to see his violin? B: Toos.'

(9) Dutch (Levelt \& Kelter 1982: 80)

A: Wie laat Paul zijn viool zien?

A: whom lets Paul his violin see

B: Aan Toos/Toos.

B: to Toos/Toos

'A: Who does Paul allow to see his violin? B: Toos.'

In the rest of this paper we use the term correspondent to refer to the parallel position in the argument structure of the antecedent and define structural match over fragments and their correspondents.

2.1 WHY STRUCTURAL MATCH? Given the content-addressable architecture of the direct-access mechanism and the Find and Align steps of ellipsis resolution, matching syntactic category and case features provide the maximally informative structure available for fragments under clausal ellipsis. That is, a fragment provides unambiguous cues about the correspondent under these conditions. It is useful to think of benefits associated with structural match in terms of efficient language processing. Hawkins $(2004,2014)$ formulates the principle of Minimize Forms (MiF), which states that efficient language processing allows linguistic forms to undergo reductions in environments where their syntactic and semantic properties can be easily assigned to them. For instance, the use of pronominal anaphora in place of lexical NPs represents reduction of the syntactic and semantic complexity of the form chosen in the sense that pronouns are less complex than lexical NPs. And in languages like Turkish and Persian typical objects (inanimate) and subjects (animate) may optionally surface as caseless, resulting in reduction of the formal complexity of the NPs expressing these objects and subjects.

Ellipsis is also reduction. Independent of the theoretical machinery one might propose for deriving elliptical constructions, their syntactic form is less than their semantics. Hawkins (2004) briefly addresses ellipsis as providing support for the idea that reduction doesn't happen just anywhere. One supportive environment is an antecedent that is structurally parallel to an ellipsis site, since this ensures that the required properties can be easily assigned to the ellipsis site. To illustrate, (10) shows Right Node Raising, a construction limited to coordination where material (here a verbal object) is shared between two conjuncts (Hawkins 2004: 94).

$$
\text { John angered and Fred amused the woman. }
$$

Assuming ellipsis of the verbal object in the left conjunct, the parser must recognize the gap and retrieve an interpretation for it. This process is supported by the fact that the ellipsis site and the antecedent are conjuncts featuring identical syntactic structure. It is now well known that ellipsis is subject to constraints involving structural parallelism (Hankamer \& Sag 1976, Hardt 1993, Kennedy 1994, Arregui, Clifton Jr., Frazier \& Moulton 2006, Frazier \& Clifton 2006, Kim, Kobele, Runner \& Hale 2011, Kertz 2013, Roberts, Matsuo \& Duffield 2013, Kim \& Runner 2018). This includes clausal ellipsis, not just in terms of syntactic parallelism between a fragment and the parallel argument (Levelt \& Kelter 1982, Culicover \& Jackendoff 2005, 2012, Chung 2013, Abels 2017a,b), but also in terms of structural parallelism between the antecedent and (the mater- 
ial containing) the ellipsis site (Merchant 2005, 2013). ${ }^{2}$ We conclude from this discussion that fragments that match the syntactic category and/or case features of their correspondents can be processed more efficiently than fragments that do not match them.

2.2 Departures From StRUCtURAL Match. Korean features two kinds of case markers, structural, examples of which we saw in Section 1, and semantic. The relevant difference between them is that semantic case markers may not be dropped from full clauses (Kim 2016). In (11), the case-marked correspondent nwukwunka-lopwuthe 'from someone' may not surface as caseless, while the fragments alternate between the matching case-marked NP and the mismatching caseless NP.

Korean

A: Phyenci-ka nwukwunka-lopwuthe wa-ss-e.

A: letter-NOM someone-from come-PST-DECL

B: Ung, Mimi-lopwuthe/Mimi.

B: yes, Mimi-from/ Mimi

'A: A letter came from someone. B: Yes, from Mimi/Mimi.'

Thus fragments, but not their correspondents, have the possibility of appearing as caseless NPs, a possibility that leads to structural mismatch. The same pattern is seen in English examples like (1), repeated here as (12), if the fragment is an NP.
A: Who are you talking to?
B: Mitchell.

Assuming that the correspondent is the PP who to, the fragment's syntactic category is mismatched with it. These data raise the question of why such mismatch is possible.

We suggest that such mismatching fragments result from a second stage of reduction. This suggestion follows from independent research on anaphora, which reveals an interaction between the form of an anaphor and the accessibility of its antecedent. Anaphors whose linguistic content is reduced (e.g., pronouns) serve to retrieve accessible phrases in language production (Arnold 2001, Arnold \& Grin 2007, Fukumura \& Van Gompel 2010, 2011, Karimi, Fukumura, Ferreira \& Pickering 2014, Ariel 1990) and in comprehension (Arnold 2008, Dahan, Tanenhaus \& Chambers 2002, Fletcher 1984, Karimi \& Ferreira 2016). Accessibility is defined as the ease with which the referent of a phrase can be accessed in memory (Bock 1982, 1987, Christianson \& Ferreira 2005, Kelly, Bock \& Keil 1986, McDonald, Bock \& Kelly 1993, Prat-Sala \& Branigan 2000 ), and is mediated by semantic and syntactic information provided by that phrase about its referent (Craik \& Tulving 1975, Fisher \& Craik 1980, Marks 1987, Hofmeister, Jaeger, Sag, Arnon \& Snider 2007, Hofmeister \& Sag 2010, Hofmeister 2011). Lexical NPs, for instance, provide more information about their referents than pronouns and hence are more accessible and more likely to be retrieved with reduced forms (e.g., pronominal anaphors or zero forms). Accessibility effects are attributed to the fact that more accessible antecedents require less linguistic

2 Structural parallelism effects are not specific to ellipsis (Kertz 2013, Roberts, Matsuo \& Duffield 2013, Sturt, Keller \& Dubey 2010). For instance, Sturt, Keller \& Dubey (2010) provide empirical evidence that the processing of structures parallel to those previously encountered in the surrounding discourse is facilitated in various syntactic configurations and is part of a general priming mechanism. 
information for successful retrieval, while less accessible antecedents require more information in the form of explicit anaphors (Fukumura \& Van Gompel 2010, Fukumura, Van Gompel, Harley \& Pickering 2011). Karimi, Fukumura, Ferreira \& Pickering (2014) demonstrate that accessibility effects are driven by how elaborated (measured in words) an antecedent is. For instance, an antecedent NP modified by a relative clause attracts more pronominal anaphors than an unmodified antecedent NP.

Given this research, mismatching fragments can be explained as reduction of morphosyntactic form triggered by accessibility effects. English fragments undergo reduction from PP to NP and Korean fragments from a case-marked NP to a caseless NP. This reduction remains a possibility so long as fragments have explicit correspondents. Recall that English fragments have difficulty dropping prepositions if their correspondents are implicit, as illustrated in (2), repeated here as (13).
A: Just doing some research.
B: *What?

The same is true of Korean: fragments do not drop structural case markers if their correspondents are implicit (see ex. (4)), an nor do they drop semantic case markers under these conditions, as in (14).

\section{(14) Korean}
A: Phyenci-ka wa-ss-e.
A: letter come-PST-DECL
B: Ung, *Mimi.
B: yes, *Mimi
'A: A letter came. B: *Yes, Mimi.'

Such implicit correspondents are minimally accessible, because they consist of no words. Implicit and explicit correspondents therefore contrast, which can be attributed to the latter being longer, and hence more accessible, by virtue of being expressed explicitly. This perspective on the identity between fragments and correspondents permits a unified processing-based account of fragments with explicit correspondents and fragments with implicit correspondents such that we predict, correctly, that reduced fragments may appear only if their correspondents are explicit. We further predict, for Korean, that of the two kinds of mismatch available when structural case markers are involved (see ex. (3) and (5)), it is case-marked correspondents paired up with reduced (caseless) fragments, rather than the reverse, that is more likely to be acceptable.

3. Experiments. In the following three acceptability judgment experiments we test three predictions on Korean data. First, matching forms of fragments and correspondents are favored over mismatching ones, if variation is permitted for fragments and correspondents. Second, the acceptability of mismatch is directional in the sense that reduced (caseless) fragments paired with unreduced correspondents are better than the reverse. Third, reduced fragments are more degraded than unreduced fragments when paired with implicit correspondents.

For all three experiments, acceptability ratings were delivered on a 7-point scale and all data were analyzed by means of regression modeling. Fifty five native Korean speakers in total took part in the experiments. 
3.1 EXPERIMENT 1: MATCH IS BETTER THAN MISMATCH. This experiment exploits the possibility for manipulating the morphosyntactic form of both fragments and correspondents in Korean, which is localized to structural case markers (accusative, genitive and nominative) (see Kim 2016). The examples below illustrate our two experimental conditions: the Match condition (matched fragment and correspondent or mismatched fragment and correspondent) and the Case Drop Location condition (caseless fragment or caseless correspondent) in a 2x2 design.
A: Mimi-ka mwues masy-ess-ni?
A: Mimi-NOM what drink-PST-QUE?
B: Cwusu.
B: juice

'A: What did Mimi drink? B: Juice.'
A: Mimi-ka mwues-ul masy-ess-ni?
A: Mimi-NOM what-ACC drink-PST-QUE?
B: Cwusu-lul.
B: juice-ACC

'A: What did Mimi drink? B: Juice.'
A: Mimi-ka mwues-ul masy-ess-ni?
A: Mimi-NOM what-ACC drink-PST-QUE?
B: Cwusu.
B: juice

'A: What did Mimi drink? B: Juice.'
A: Mimi-ka mwues masy-ess-ni?
A: Mimi-NOM what drink-PST-QUE?
B: Cwusu-lul.
B: juice-ACC

'A: What did Mimi drink? B: Juice.'

We fit the data to a linear mixed-effects model that included Match and Case Drop Location as fixed effects, as well as random intercepts for participants and items. There was a main effect of Match, such that pairs of mismatched fragments and correspondents received lower ratings than matched ones $(\mathrm{p}<.05)$. We did not observe any reliable acceptability difference between caseless and case-marked fragments independent of the realization of correspondents $(p=.84)$. However, there was an interaction between Match and Case Drop Location. Mismatched fragments and correspondents were judged better when fragments were caseless than when correspondents were caseless $(\mathrm{p}<.01)$. These results confirm the first prediction (match is judged better than mismatch), as well as the second prediction (the pairing of unreduced correspondents with reduced fragments is judged better than the reverse). Furthermore, the interaction between Match and Case Drop Location represents the first indication of accessibility effects.

3.2 EXPERIMENT 2: CASE-MARKED FRAGMENTS ARE BETTER THAN CASELESS FRAGMENTS WITH IMPLICIT PARALLEL ARGUMENTS. In this experiment, we manipulated the morphosyntactic form of fragments, while keeping all correspondents implicit. The hypothesis tested was that implicit 
correspondents do not easily permit reduction of fragments, closely tracking the English pattern where sprouting fragments are rarely realized as NPs if the correspondents are implicit PPs. The examples below illustrate the only experimental condition, Case Drop.

(19) A: Chelswu-ka pat-ass-ney.

A: Chelswu-NOM receive-PST-DECL

B: Ung, sangkum-ul.

B: yes, prize-ACC

'*Chelswu received. B: Yes, a prize.'

(20) A: Chelswu-ka pat-ass-ney.

A: Chelswu-NOM receive-PST-DECL

B: Ung, sangkum.

B: yes, prize

'*Chelswu received. B: Yes, a prize.'

The model fitted to these data included Case Drop as the only fixed effect and random intercepts for participants and items. Consistent with our hypothesis, there was a main effect of Case Drop such that caseless fragments were rated lower than case-marked ones $(p<.01)$. This result supports the idea that implicit correspondents disfavor reduction of the morphosyntactic form of fragments, aligning the behavior of Korean fragments with that of English fragments.

3.3 EXPERIMENT 3: CASELESS FRAGMENTS ARE BETTER WITH EXPLICIT CORRESPONDENTS THAN IMPLICIT ONES. This experiment focuses on Korean semantic case markers. We contrasted explicit and implicit correspondents (Type condition) and crossed them with the Case Drop condition (caseless or case-marked fragments), as in (21)-(24).

(21) A: Phyenci-ka nwukwunka-lopwuthe wa-ss-e.

A: letter-NOM someone-from come-PST-DECL

B: Ung, Mimi-lopwuthe.

B: yes, Mimi-from

'A: A letter came from someone. B: Yes, from Mimi.'

(22) A: Phyenci-ka nwukwunka-lopwuthe wa-ss-e.

A: letter-NOM someone-from come-PST-DECL

B: Ung, Mimi.

B: yes, Mimi

'A: A letter came from someone. B: Yes, Mimi.'

(23) A: Phyenci-ka wa-ss-e.

A: letter-NOM come-PST-DECL

B: Ung, Mimi-lopwuthe.

B: yes, Mimi-from

'A: A letter came. B: Yes, from Mimi.'

(24) A: Phyenci-ka wa-ss-e.

A: letter-NOM come-PST-DECL

B: Ung, Mimi. 
B: yes, Mimi

'A: A letter came. B: Yes, *Mimi.'

We fitted a linear mixed-effects model to the data, with Type and Case Drop as fixed effects and random intercepts for participants and items. We observed no main effects, although the ratings for caseless fragments trended in the direction of lower acceptability than casemarked fragments, and so did ratings for items with implicit correspondents compared to items with explicit correspondents. There was, however, an interaction between Case Drop and Type: caseless fragments were worse when their correspondents were implicit than when they were explicit $(\mathrm{p}<.01)$.

Additional analysis reveals that the statistically significant interaction was carried by the items featuring implicit correspondents. That is, the penalty for caseless fragments reached statistical significance for this set of items $(p<.01)$, but not for the items that featured explicit correspondents $(p=.22)$. The behavior of items featuring explicit correspondents here replicates the finding from Experiment 1 - that, all else being equal, the acceptability of fragments is not impacted by their form when correspondents are explicit. More generally, the current results offer evidence that semantic and structural case markers are aligned with respect to the possibilities for reduction of the morphosyntactic form of fragments.

4. General discussion. Our experimental results bear on the question of what kind of identity holds between a fragment and its antecedent. We have proposed that the morphosyntactic form of a fragment impacts the process of retrieving an interpretation for it, a process which has been shown by Martin and McElree (2011) to involve direct-access operations. We have made three assumptions as part of this proposal. First, we have assumed that elements relevant for direct-access operations are a fragment and the corresponding position in the antecedent clause - a fragment's correspondent. Second, we have suggested that where a correspondent and fragment may be realized in more than one way, structural match between them is preferred over mismatch. Third, we have also assumed that fragments may undergo form reduction, resulting in them being morphosyntactically less complex than their correspondents. This set of assumptions allows us to define identity over fragments and their correspondents.

The current study has supported these assumptions. Experiment 1 has demonstrated that fragments share their correspondents' morphosyntactic features: if case drop is available for correspondents, it is also available for fragments, supporting our first assumption. This experiment has also confirmed the existence of structural parallelism effects, where morphosyntactic match between fragments and correspondents is preferable over mismatch. Finally, we have offered evidence that reduction of the morphosyntactic form of fragments is favored over reduction of the morphosyntactic form of correspondents in cases of mismatch. The directionality of the acceptability ratings here lends support to the idea that fragments can get reduced when they have accessible correspondents, as predicted by MiF, one of the principles of efficient language processing articulated in Hawkins $(2004,2014)$. This prediction finds further support in Experiments 2-3, where reduction of the morphosyntactic form of fragments is possible even if it is not possible for explicit correspondents, and it is degraded if correspondents are implicit. Together, these results speak in favor of the morphosyntactic form of fragments serving as a retrieval cue that guides the process of accessing correspondents. 
A question raised by the current results is how grammatical reduced fragments are when they violate structural match. Our findings point to structural match as the most acceptable setup, while reduction of the morphosyntactic form of fragments incurs a more severe penalty when these fragments have implicit corespondents than otherwise. Taking structural match as the basic case then, we arrive at a structural constraint on fragments: the morphosyntactic form of a fragment must be matched to the morphosyntactic form of a correspondent. What remains is the problem of accounting for violations of structural match. If our proposal is on the right track, then independently motivated principles of efficient language processing can be invoked to account for them as instances of acceptable ungrammaticality.

5. Conclusion. We have presented evidence in favor of a structural constraint on Korean fragments such that matching fragments and corespondents are the most acceptable configuration. Our proposal builds on cue-based accounts of clausal ellipsis, where the parser has direct access to content-addressable representations stored in memory while interpreting an ellipsis site. We have proposed that the parser uses morphosyntactic cues provided by a fragment to locate a correspondent directly, a process that is facilitated by structural match between a fragment and correspondent. However, the structural constraint is violable, creating a need to account for cases of mismatch between fragments and correspondents. Toward this purpose, we have appealed to an independently motivated principle of efficient language processing, which permits reduction of the morphosyntactic form of fragments just in case their relationship with correspondents can be easily computed. While we suggest that reduced fragments are ungrammatical but acceptable, we leave a fuller answer to this question for future research.

\section{References}

Abels, Klaus. 2017a. Movement and islands. In Jeroen van Craenenbroeck \& Tanja Temmerman (eds.), The Oxford handbook of ellipsis, chapter 15. Oxford: Oxford University Press.

Abels, Klaus. 2017b. On the interaction of P-stranding and sluicing in Bulgarian. In Olav Mueller-Reichau \& Marcel Guhl (eds.), Aspects of slavic linguistics: Formal grammar, lexicon and communication, volume 16 of Language, Context and Cognition. Berlin: De Gruyter Mouton.

Ariel, Mira. 1990. Accessing Noun Phrase Antecedents. London-New York: Routledge.

Arnold, Jennifer E. \& Zenzi M. Griffin. 2007. The effect of additional characters on choice of referring expression: Everyone counts. Journal of Memory and Language 56. 521-536.

Arnold, Jennifer E. 2001. The effect of thematic roles on pronoun use and frequency of reference continuation. Discourse Processes 31. 137-162.

Arnold, Jennifer E. 2008. Reference production: Production-internal and addressee-oriented processes. Language and Cognitive Processes 23. 495-527.

Arregui, Ana, Charles Clifton Jr., Lyn Frazier \& Keir Moulton. 2006. Processing elided verb phrases with flawed antecedents: The Recycling Hypothesis. Journal of Memory and Language 55. 232-246. https://doi:10.1016/j.jml.2006.02.005

Barros, Matthew. 2014. Sluicing and identity in ellipsis. Doctoral dissertation. Rutgers University.

Bock, J. Kathryn. 1982. Toward a cognitive psychology of syntax: information processing contributions to sentence formulation. Psychological Review 89. 1-47. 
Bock, J. Kathryn. 1987. An effect of the accessibility of word forms on sentence structures. Journal of Memory and Language 26. 119-137.

Christianson, Kiel \& Fernanda Ferreira. 2005. Conceptual accessibility and sentence production in a free word order language (Odawa). Cognition 98. 105-135.

Chung, Sandra. 2006. Sluicing and the lexicon: The point of no return. In R. T. Cover and Y. Kim (eds.), BLS 31: General Session and Parasession on Prosodic Variation and Change, 73-91.

Chung, Sandra. 2013. Syntactic identity in sluicing: How much and why. Linguistic Inquiry 44. 1-44. https://doi.org/10.1162/LING_a_00118.

Craik, Fergus I. M. \& Endel Tulving. 1975. Depth of processing and the retention of words in episodic memory. Journal of Experimental Psychology: General 104. 268-294.

Culicover, Peter. \& Ray Jackendoff. 2005. Simpler syntax. New York: Oxford University Press.\%

Culicover, Peter. \& Ray Jackendoff. 2012. Same-except: A domain-general cognitive relation and how language expresses it. Language 88. 305-340. https://doi.org/10.1353/lan.2012.0031.

Dahan, Delphine, Michael K. Tanenhaus, M. K. \& Craig G. Chambers. 2002. Accent and reference resolution in spoken-language comprehension. Journal of Memory and Language 47. 292-314.

Fisher, Ronald P. \& Fergus I. M. Craik. 1980. The effects of elaboration on recognition memory. Memory and Cognition 8. 400-404.

Fletcher, Charles R. 1984. Markedness and topic continuity in discourse processing. Journal of Verbal Learning and Verbal Behavior 23. 487-493.

Frazier, Lyn \& Charles Clifton Jr. 2006. Ellipsis and discourse coherence. Linguistics and Philosophy 29. 315-346.

Fukumura, Kumiko \& Roger P. G. Van Gompel. 2010. Choosing anaphoric expressions: Do people take into account likelihood of reference? Journal of Memory and Language 62. 52-66.

Fukumura, Kumiko \& Roger P. G. Van Gompel. 2011. The effects of animacy in the choice of referring expressions. Language and Cognitive Processes 26. 1472-1504.

Fukumura, Kumiko, Roger P. G. Van Gompel, Trevor Harley \& Martin J. Pickering. 2011. How does similarity-based interference affect the choice of referring expression? Journal of Memory and Language 65. 331-344.

Ginzburg, Jonathan \& Ivan A. Sag. 2000. Interrogative investigations. The form, meaning and use of English interrogative. Stanford, CA: CSLI Publications. [Distributed by U. Chicago Press].

Ginzburg, Jonathan. 2012. The interactive stance. Oxford: Oxford University Press.

Hankamer, Jorge \& Ivan A. Sag. 1976. Deep and surface anaphora. Linguistic Inquiry 7. 391-428.

Hardt, Daniel. 1993. Verb phrase ellipsis: Form, meaning, and processing. Philadelphia: University of Pennsylvania dissertation.

Hawkins, John A. 2004. Efficiency and complexity in grammars. Oxford: Oxford University Press.

Hawkins, John A. 2014. Cross-linguistic variation and efficiency. Oxford: Oxford University Press. 
Hofmeister, Philip, T. Florian Jaeger, Ivan A. Sag, Inbal Arnon \& Neal Snider. 2007. Locality and accessibility in wh-questions. In S. Featherston \& W. Sternefeld (eds.), Roots: Linguistics in Search of its Evidential Base, 185-206. Berlin: Mouton de Gruyter.

Hofmeister, Philip, T. Florian Jaeger, Inbal Arnon, Ivan A. Sag \& Neal Snider. 2013. The source ambiguity problem: distinguishing the effects of grammar and processing on acceptability judgments. Language and Cognitive Processes 28. 48-87.

Hofmeister, Philip \& Ivan A. Sag. 2010. Cognitive constraints and island effects. Language 86. 366-415.

Hofmeister, Philip. 2011. Representational complexity and memory retrieval in language comprehension. Language and Cognitive Processes 26. 376-405.

Jacobson, Pauline. 2016. The short answer: Implications for direct compositionality (and vice versa). Language 92. 331-375.

Karimi, Hossein, Kumiko Fukumura, Fernanda Ferreira \& Martin J. Pickering. 2014. The effect of noun phrase length on the form of referring expressions. Memory and Cognition 42. 9931009. https://doi.org/10.3758/s13421-014-0400-7.

Karimi, Hossein \& Frenanda Ferreira. 2016. Informativity renders a referent more accessible: Evidence from eyetracking. Psychonomic Bulletin \& Review 23. 507-525.

Kelly, Michael H., J. Kathryn Bock \& Frank C. Keil. 1986. Prototypicality in a linguistic context: Effects on sentence structure. Journal of Memory and Language 25. 59-74.

Kennedy, Chris. 1994. Argument contained ellipsis. Linguistics Research Center Report LRC-94-03, University of California, Santa Cruz.

Kertz, Laura. 2013. Verb phrase ellipsis: The view from information structure. Language 89. 390-428. https://doi.org/10.1353/lan.2013.0051.

Kim, Christina S., Gregory M. Kobele, Jeffery T. Runner \& John T. Hale. 2011. The acceptability cline in VP ellipsis. Syntax 4. 318-54. https://doi.org/10.1111/j.1467-9612.2011.00160.x.

Kim, Christina S. \& Jeffery T. Runner. 2018. The division of labor in explanations of Verb Phrase ellipsis. Linguistics and Philosophy 41. 41-85. https://doi.org/10.1007/ s10988-017-9220-0.

Kim, Jong-Bok. 2015. Syntactic and semantic identity in Korean sluicing: A direct interpretation approach. Lingua 166. 260-293.

Kim, Jong-Bok. 2016. The syntactic structures of Korean: A construction grammar perspective. Cambridge: Cambridge University Press.

Kobele, Gregory M. 2015. LF-copying without LF. Lingua 166. 236-259. https://doi.org/ 10.1016/j.lingua.2014.08.006.

Lee, Hanjung. 2016. Usage probability and subject-object asymmetries in Korean case ellipsis: Experiments with subject case ellipsis. Journal of Linguistics 52. 70-110. https://doi.org/ 10.1017/S0022226715000079.

Levelt, Willem \& Stephanie Kelter. 1982. Surface form and memory in question answering. Cognitive Psychology 14. 78-106.

Marks, William. 1987. Retrieval constraints on associative elaborations. Journal of Experimental Psychology: Learning, Memory, and Cognition 13. 301-309.

Martin Andrea E., \& Brian McElree. 2008. A content-addressable pointer underlies comprehension of verb-phrase ellipsis. Journal of Memory and Language 58. 879-906. 
Martin Andrea E., \& Brian McElree. 2009. Memory operations that support language comprehension: Evidence from verb-phrase ellipsis. Journal of Experimental Psychology: Learning, Memory and Cognition 35. 1231-1239. https://doi.org/10.1037/a0016271.

Martin, Andrea E. \& Brian McElree. 2011. Direct-access retrieval during sentence comprehension: Evidence from sluicing. Journal of Memory and Language 64. 327-343. https://doi.org/ 10.1016/j.jml.2010.12.006.

McDonald, Janet L., J. Kathryn Bock \& Michael H. Kelly. 1993. Word and world order: Semantic, phonological and metrical determinants of serial position. Cognitive Psychology 25. 188230.

Merchant, Jason. 2004. Fragments and ellipsis. Linguistics and Philosophy 27. 661-738.

Merchant, Jason. 2005. Revisiting syntactic identity conditions. Workshop on ellipsis, University of California, Berkeley.

Merchant, Jason. 2013. Voice and ellipsis. Linguistic Inquiry 44. 77-108. https://doi.org/10.1162/ LING_a_00120.

Prat-Sala, Merce \& Holly P. Branigan. 2000. Discourse constraints on syntactic processing in language production: A cross-linguistic study in English and Spanish. Journal of Memory and Language 42. 168-182.

Roberts, Leah, Ayumi. Matsuo \& Nigel Duffield. 2013. Processing VP-ellipsis and VP-anaphora with structurally parallel and nonparallel antecedents: An eye-tracking study. Language and Cognitive Processes 28. 29-47. https://doi.org/10.1080/01690965.2012.676190.

Sag, Ivan A. \& Joanna Nykiel. 2011a. Remarks on sluicing. In Proceedings of the 11th HPSG Conference, ed. S. Mueller, 188-208. Stanford, CA: CSLI Publications.

Sag, Ivan A. \& Joanna Nykiel. 2011b. We can't hear the strikeouts either: Sluicing without deletion. Talk presented at Ellips'Event. Stanford university.

Sturt, Patrick, Frank Keller \& Amit Dubey. 2010. Syntactic priming in comprehension: Parallelism effects with and without coordination. Journal of Memory and Language 62. 333-351. https://dx.doi.org/10.1016/j.jml.2010.01.001.

Van Dyke, Julie A. \& Brian McElree. 2006. Retrieval interference in sentence comprehension. Journal of Memory and Language 55. 157-166.

Van Dyke, Julie A. \& Brian McElree. 2011.Cue-dependent interference in comprehension. Journal of Memory and Language 65. 247-263. https://doi.org/10.1016/j.jml.2011.05.002.

Van Dyke, Julie. A. 2007. Interference effects from grammatically unavailable constituents

dur- ing sentence processing. Journal of Experimental Psychology: Learning, Memory, and Cognition 33. 407-430.

Weir, Andrew. 2014. Fragments and clausal ellipsis. Doctoral dissertation, University of Massachusetts Amherst. 